\title{
Diversidade e Democratização no Cinema e no Audiovisual Brasileiro: Um Panorama de 2001 a 2021
}

\section{Thiago Venanzoni}

Doutor em Meios e Processos

Audiovisuais pela Escola de

Comunicações e Artes da Universidade de São Paulo (ECA-USP). Docente Audiovisual no Centro Universitário Faculdades Integradas Alcântara Machado e Faculdades de Artes Alcântara Machado (FIAM-FAAM) E-mail: thiago.venanzoni@gmail.com
Resumo: O cinema e o audiovisual brasileiro passaram por relevantes transformações institucionais ao longo dos 20 primeiros anos do século XXI, o que certamente nos leva a pensar sobre o impacto dessas mudanças no campo audiovisual. Este artigo apresentará algumas dessas perspectivas a partir do alargamento do campo de produção e das alterações nos níveis da organização que estão indicadas, bem como os projetos do setor e as suas transformações. Para a construção desse panorama de vinte anos e para as análises de produção, faremos uso de dois articuladores conceituais presentes nas políticas públicas destinadas ao campo audiovisual: a perspectiva da diversidade e da democratização. Ambos articuladores estão vinculados à ascensão e à presença de novos territórios de produção audiovisual e à emergência de coletivos no horizonte dessas produções do cinema e do audiovisual brasileiro contemporâneo.

Palavras-chave: diversidade cultural, democratização do audiovisual, audiovisual brasileiro contemporâneo, coletivos audiovisuais, políticas públicas.

Diversidade y Democratización en el Cine y Audiovisual Brasileño: Un Panorama de 2001 a 2021

Resumen: El cine y el audiovisual brasileño sufrieron importantes transformaciones institucionales durante los 20 años del siglo XXI, lo que sin duda nos lleva a pensar en el impacto de estos cambios en el campo audiovisual. Este artículo presentará algunas de estas perspectivas desde la expansión del campo productivo y los cambios en niveles organizacionales que se señalan, así como en los proyectos del sector y sus transformaciones. Para construir este panorama de dos décadas y el análisis de la producción, se utilizarán dos articuladores conceptuales presentes en las políticas públicas dirigidas al campo audiovisual: la perspectiva de la diversidad y la de democratización. Ambas están vinculadas al surgimiento y presencia de nuevos territorios de producción audiovisual, y al surgimiento de colectivos en el horizonte de estas producciones audiovisuales y cinematográficas brasileñas contemporáneas.

Palabras-clave: diversidad cultural, democratización audiovisual, audiovisual brasileño contemporáneo, colectivos audiovisuales, políticas públicas.

Diversity and Democratization in Brazilian Cinema and Audio-visual: An Overview from 2001 to 2021

Abstract: Brazilian cinema and audio-visual underwent relevant institutional transformations over the first 20 years of the $21^{\text {st }}$ century, which certainly leads us to think about the impact of these changes in the audio-visual field. This article will present some of these perspectives from the expansion of the field of production and the changes in organizational levels that are indicated, as well as the sector's projects and their transformations. To build this twenty-year panorama and for the production analyses, we will make use of two conceptual articulators present in public policies aimed at the audio-visual field: the perspective of diversity and democratization. Both articulators are linked to the rise and the presence of new territories of audio-visual production and the emergence of collectives on the horizon of these contemporary Brazilian cinema and audio-visual productions.

Keywords: cultural diversity, audio-visual democratization, contemporary Brazilian audiovisual, audio-visual collectives, public policies. 


\section{Introdução}

Para se traçar um panorama que corresponda ao cinema e ao audiovisual brasileiro nas duas décadas do século XXI, é impossível passar impunemente pelo marco que foi a criação da Agência Nacional do Cinema (Ancine) em 2001. A medida provisória que consolidou a agência em 6 de setembro de 2001 corresponde a uma articulação do setor do audiovisual ao longo da década anterior que construiu o seu ideal no III Congresso do Cinema Brasileiro, ocorrido um ano antes da criação da Ancine, a partir do relatório final exposto no evento. Entre os marcos diagnosticados pelos presentes havia a necessidade de organizar a autossuficiência do setor audiovisual, que, naquele momento, limitava-se - em relação às políticas públicas do setor - à Lei do Audiovisual atrelada às formas de atuação indireta da Lei de Incentivo à Cultura, conhecida também como Lei Rouanet.

Sendo o mecanismo de atuação dessa lei investimentos indiretos na cultura, uma relação próxima ou o acesso às normativas das empresas patrocinadoras por parte das produtoras que captavam financiamento para as suas produções eram uma necessidade. De forma evidente, esse dinamismo de incentivo indireto favorecia um universo muito restrito de produtoras audiovisuais em regiões e territórios igualmente restritos. Nos anos 1990, no nomeado Cinema da Retomada, a perspectiva era de que as obras fossem financiadas em maior parte por empresas privadas ou público-privadas por meio de incentivos fiscais garantidos pelas leis. Por esse motivo, notava-se também uma repetição de lugares nas produções audiovisuais. Se por um momento específico esse modelo foi concebido como um desafogo diante do encerramento da Empresa Brasileira de Filmes S.A. (Embrafilme), em 1990, ao longo dessa década, já havia sido diagnosticado por produtores, acadêmicos e pessoas engajadas com o tema a dificuldade em formar uma nova industrialização do cinema e do audiovisual brasileiro e a restrição que o mecanismo de incentivo fiscal provocava ao campo.

A criação de um órgão central consensual do campo, a partir de uma hegemonia que se formou ao longo da década anterior, de acordo com a análise do pesquisador Marcelo Ikeda (2015), não contribuiu decisivamente para a mudança das políticas públicas nos rumos que os incentivos indiretos já direcionavam. Segundo lkeda, a inocorrência se deu a princípio por uma associação difusa de paradoxos existentes na própria noção do mercado audiovisual para as gestões públicas. À essa análise acrescentamos também a ausência de um projeto nacional naquele instante que deixasse a agência ausente de mecanismos institucionais que possibilitassem alterações no cenário de produção do cinema e do audiovisual.

Desse modo, os mecanismos de incentivo fiscal, cujas limitações já eram bastante visíveis antes mesmo da criação da ANCINE, continuaram como a principal fonte de financiamento das obras cinematográficas brasileiras. Simplesmente através do fomento, ou de normas expedidas para o aperfeiçoamento da apresentação de projetos incentivados, não foi possível para a agência interferir de fato nos rumos do mercado cinematográfico. (Ikeda, 2015, p. 171)

Diante da realidade da não suficiência do audiovisual, notada logo nos primeiros anos da criação da Ancine, articulada a uma realidade de assombramento global da mundialização e da desterritorialização das produções audiovisuais, o que construiu um espaço de disparidade entre as produções nacionais frente ao consumo de obras externas, houve a formação de novas articulações que passaram a ocupar o espaço do debate no setor do cinema e do audiovisual. Nesse sentido, a criação da agência não passou incólume às mudanças nos panoramas global e social, mas justamente em um movimento de ampliação da participação democrática no emblema da diversidade como articuladora dessas políticas.

Dessa forma, a estratégia a ser pensada era a de como organizar formas de produção que pudessem se contrapor, em algum nível, à derrocada das produções culturais diante da ocupação das narrativas globais em nosso mercado 
consumidor. Essas estratégias se organizaram em torno das ações e políticas do audiovisual, mas de forma ampla e integrada a outras ações, envolvendo, assim, todo o setor cultural e abrindo um grande debate sobre a produção de um plano nacional do setor. Logo, entendia-se que as ações mais efetivas necessitavam ser articuladas junto a um conjunto mais amplo e em contraposição a uma hegemonia globalizante, ou seja, formando um plano nacional e as suas estratégias de ação.

\section{Mudanças significativas no horizonte cultural}

A diversidade durante 2001 e 2021, período conhecido como o novo passo da globalização, torna-se um emblema discursivo no contemporâneo, como afirma o sociólogo Renato Ortiz (2015). Surge a partir desse emblema um mal-estar da e na contemporaneidade como forma mobilizadora dos debates sociais, principalmente sobre a diversidade como matéria cotidiana. 0 malestar emerge em tempos de reinvenção do espaço, em que "símbolos e signos culturais adquirem uma feição desterritorializada, descolados de suas cores nacionais ou regionais, redefinindo-se no âmbito da modernidade-mundo" (Ortiz, 2015, p. 10). Ou seja, a dimensão desterritorializada da globalização cria uma unificação que, de acordo com Ortiz, oferece um mal-estar sem resolução. Dessa maneira, segundo o teórico, não se encontra razão no debate comum do senso prático e das mídias, isto é, se a diversidade é boa ou ruim para os vínculos sociais ou se devemos ser mais diversos ou menos diversos, como se fosse possível avaliar essa questão social. Entretanto, Ortiz apresenta outro paradigma: "como ser diverso em uma sociedade globalizada?" (Ortiz, 2015, p. 11). Ao mudar a pergunta muda-se, igualmente, a resposta e as buscas que devemos perseguir para compreender tal emblema contemporâneo.

Para sair dessas armadilhas da globalização, o país optou pelo fortalecimento territorial das iniciativas culturais, ocorridas em iniciativas diretas e indiretas, a partir de políticas públicas em conjunto com o setor cultural. Foi justamente essa assimilação contextual que foi relevante na elaboração dos planos de ações, que tinham uma emergência expressa em contrariedade ao avanço global de hegemonias culturais que provocariam, em pouco tempo, o desaparecimento das marcas subjetivas da diversidade, escancarando a necessidade de elaboração de um plano. O Plano Nacional de Cultura (PNC) foi concebido,

[...] portanto, em um contexto político em que ganham força várias iniciativas voltadas ao fortalecimento de relações internacionais mais solidárias, com as quais o Brasil deve dialogar e contribuir. Pois estas articulações são imprescindíveis para lidar com uma conjuntura de tensão entre o local e o global, que expressa problemas e oportunidades inéditos. As novas tecnologias digitais de comunicação e informação possibilitam uma integração econômica mundial de características e alcance sem precedentes. Porém, este processo é acompanhado por profundos sentimentos de desconexão, insegurança e segregação. (Ministério da Cultura, 2007, p. 8)

Há nessa compreensão contextual um cenário que se colocaria de forma mais radical se não fossem encontradas perspectivas de contraposição ao assolamento global que o digital propicia em suas trocas culturais e simbólicas de unificações identitárias e segregações. Entretanto, ao se imaginar um plano nacional que aglutinasse ações e perspectivas para a promoção das diversidades e a democratização no setor cultural, levava-se em consideração, também, as novas tecnologias interacionais e comunicacionais em apropriações de novas linguagens. Diz o plano:

Por outro lado, as tecnologias não favorecem somente os interesses do grande mercado, inclusive o cultural. Elas também proporcionam novos fluxos de experimentação artística e oportunidades de valorização de tradições culturais específicas, combinada ao uso criativo dos mais recentes recursos científicos e tecnológicos. Neste sentido, o PNC busca contemplar as dinâmicas emergentes no mundo contemporâneo, sem deixar de atender às manifestações históricas e consolidadas. (Ministério da Cultura, 2007, p. 9) 
A partir dessa dimensão discursiva que ordena a construção do PNC, em que se considera o fortalecimento e a promoção das produções locais como fundamentais na valorização das diversidades, o território passa a ser o eixo fundamental das ações no setor cultural. Esse atendimento ao plano, ainda que os processos dentro do setor audiovisual se diferenciassem do que havia sido pensado nas convenções culturais - até pela existência de uma agência exclusiva para esse setor -, não deixa também de impactar os processos audiovisuais e de evidenciar uma contrahistória do cinema e do audiovisual no alargamento do campo de produção em que se produz esse tipo de conteúdo, de quem pode produzir nele e quais narrativas emergem dessa nova condição.

Antes da expansão desse debate nas políticas culturais - a partir de 2005 com a criação do Sistema Nacional de Cultura (SNC) e do regimento da Convenção Cultural, em 2006 -, vale ressaltar a existência de alguns projetos locais e regionais que construíam, anteriormente ao plano, um horizonte de fortalecimentos das diversidades sociais e culturais e incentivavam as práticas artríticas como vetores sociais e de proteção às populações vulneráveis. Justamente em 2006, coincidindo às criações de outros sistemas de financiamento e organização no setor cultural, foi constituído o Fundo Setorial do Audiovisual (FSA), que englobaria os financiamentos e recursos que se voltavam à produção audiovisual no país, ou seja, ferramentas de autofinanciamento. Além da contribuição da Contribuição para o Desenvolvimento da Indústria Cinematográfica Nacional (Condecine), atualmente o fundo também é constituído do Fundo de Fiscalização das Telecomunicações (Fistel), o principal fundo dentro de uma rede de receitas advindas de concessões e permissões no âmbito estatal.

O aumento da capacidade de investimentos no cinema nacional, justamente por ampliar a arrecadação, algo que o FSA conseguiu proporcionar devido à mudança em seu modelo de arrecadação, como pode ser visto pela execução orçamentária na Figura 1, e à sua diminuição considerável em 2020 por uma intervenção política perversa e adversa ao setor por parte do governo de Jair Bolsonaro, que represou financiamentos por editais já aprovados, agindo, assim, contra a lei, e realizou um revisionismo torpe, restrito e antiquado ao histórico do setor cultural por meio de bloqueio dos incentivos ao setor não apenas audiovisual, mas também ao setor cultural como um todo.
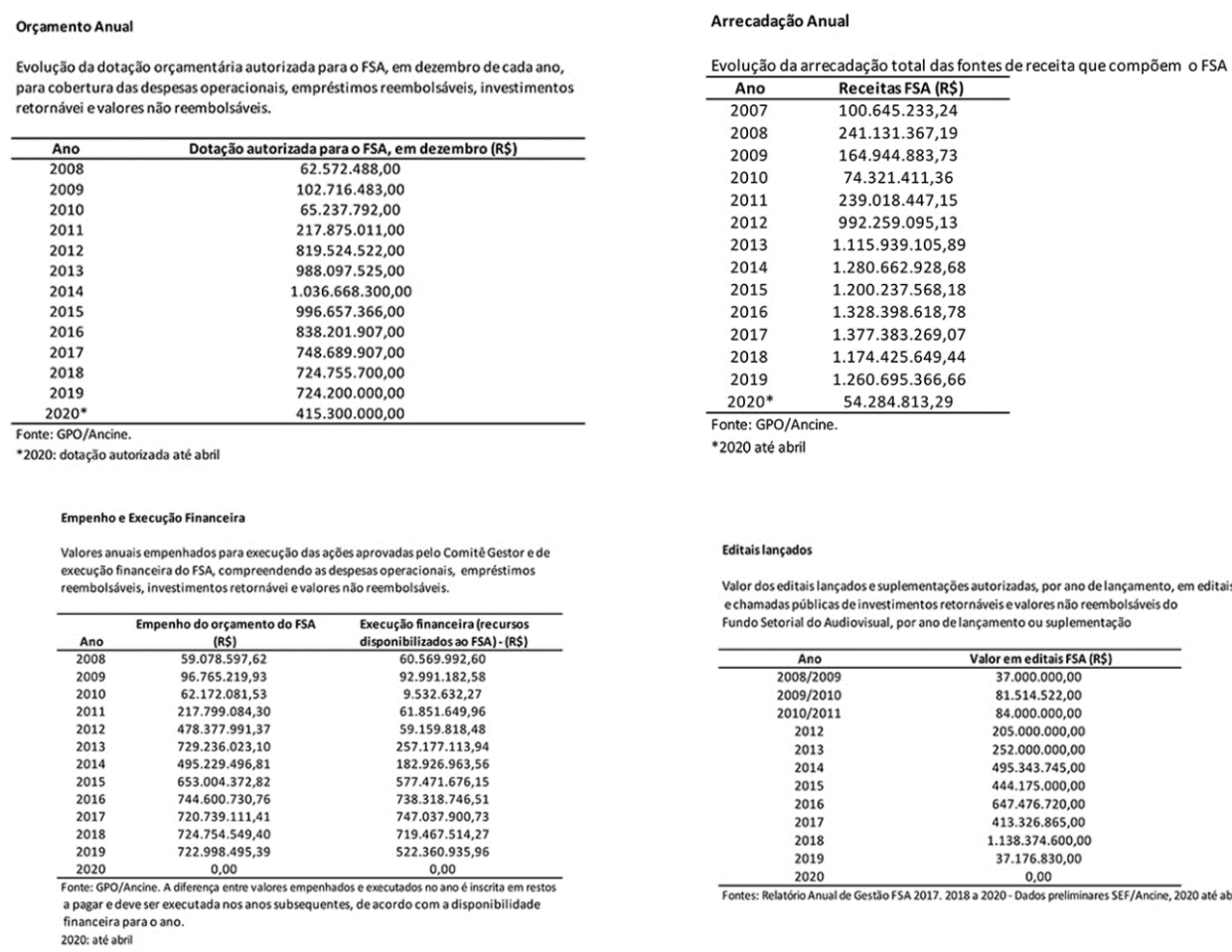

Figura 1 Execuções orçamentárias do FSA

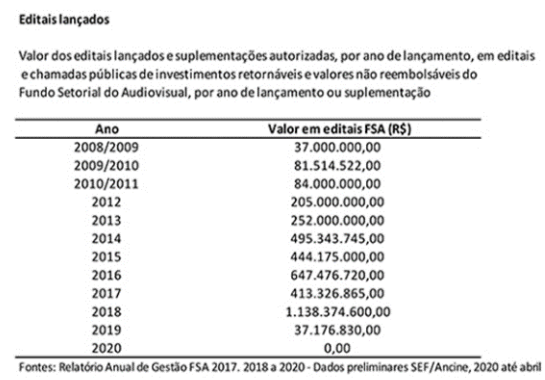


${ }^{1}$ Para um debate mais aprofundado sobre a relação da lei e seu impacto no setor cultural, ver Morais (2019).
Importante ressaltar que outras medidas foram relevantes para o aumento dessa arrecadação, como a criação da Lei no 12.485/11 que instituiu uma cota mínima de três horas e trinta minutos de exibição de produção nacional em emissoras da televisão por assinatura no Brasil - sendo por isso também conhecida como a Lei da TV Paga. Tal lei reorganizou o setor no país, aumentando a sua produtividade a partir de linhas de créditos específicas do FSA $^{1}$. Outro ponto da lei diz respeito à democratização do acesso ao financiamento, que deveria ocorrer da forma almejada, isto é, organizando novos espaços de produção. Consideramos em nossa análise temporal desses 20 anos do século XXI que um fenômeno emergido dessas ações de políticas públicas culturais é a presença, em níveis de produção, de coletivos audiovisuais.

Assim, organizamos essas produções em três níveis, colocando-as como um fenômeno não apenas no sentido das materialidades audiovisuais e das narrativas produzidas nesse período, mas também no sentido discursivo, marca desse processo. O primeiro nível trata da materialização do discurso, ou seja, a alteração da percepção de produções que poderiam, em outros contextos, serem praticadas e organizadas de outras maneiras. São produções que se transformaram em coletivas a partir de demandas locais e por incluírem nelas pessoas não produtoras.

Há ao menos três produções existentes nessa última década que demonstram claramente essa tradução contextual e que surgem em um momento de ampliação de maior investimento do FSA no cinema nacional. São elas: Era o hotel Cambridge (2017), de Eliane Caffé, produzido coletivamente com a ocupação Cambridge e os integrantes do Movimento Sem Teto do Centro (MSTC), Espero tua (re)volta, de 2019, de Eliza Capai, produzido com os secundaristas de São Paulo, e Um filme de verão, de 2019, de Jô Serfaty, com a participação dos jovens de Rio das Pedras e do Vidigal, territórios do Rio de Janeiro.

Além da recorrência discursiva em torno das produções coletivas, que incluem nas suas etapas de produção jovens, ocupantes sem teto e secundaristas como mediadores e realizadores dessas narrativas, identifica-se nessas produções a dimensão do local como um saber às produções, visto que são os espaços das ocupações, das escolas e das comunidades que constroem o local da produção e a maneira com que o filme será feito.

Acho que tudo nasceu do que a gente aprendeu na participação do movimento, no compartilhar das reuniões. A gente começou a entender o valor de uma ação participativa. Vimos e aprendemos como se dá a força de um coletivo, de uma comunidade. O que é incrível é que, no caso da Carmen e do movimento de moradia, o coletivo é estruturado para dar voz ao indivíduo. Normalmente você acha que o coletivo apaga as individualidades, mas o fato de você ter aquela comunidade, aquela coletividade, dá uma sensação de individualidade tremenda. Você pode ser quem você é. (Caffé, 2017, p. 256)

Ou seja, a importância do local é fundamental na produção e na elaboração desse cinema recente nacional e demonstra uma recorrência de prática e sentido. Como afirmado, tais produções mencionadas acima se colocam como materialidades discursivas justamente porque essas produções poderiam ser realizadas de outras formas e ainda assim teriam, como tiveram, financiamentos para serem realizadas. O que chama a atenção para esse fenômeno, portanto, é o conjunto de narrativas que se abriram ao coletivo em um novo contexto do cinema, do audiovisual e de suas políticas. Para afirmar essa condição, basta olhar para o índice da presença de produtoras e produtores no Rio de Janeiro e em São Paulo (Figura 2). 


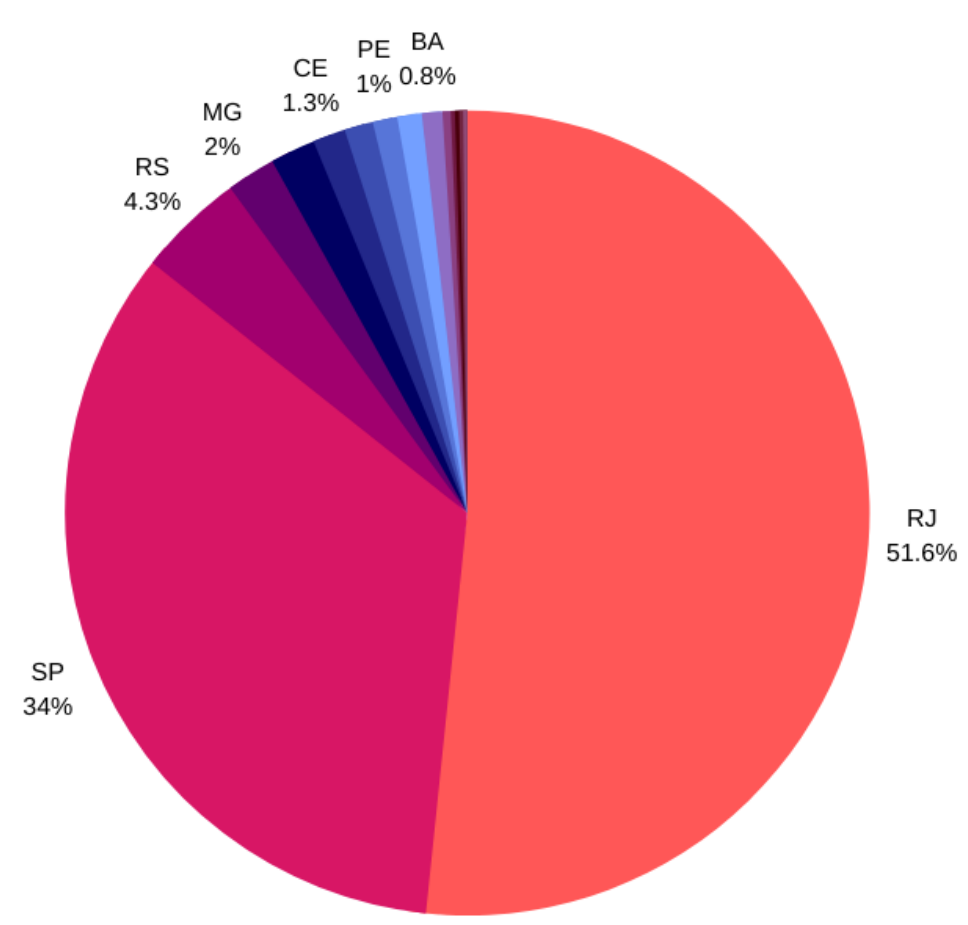

Dados: Observatório Brasileiro do Cinema e do Audiovisual

Figura 2 Dados de investimentos para produções audiovisuais entre os anos de 1995 e 2010 Nota: dados coletados e organizados pela pesquisa a partir do Observatório Brasileiro de Cinema e Audiovisual (OCA) da própria Ancine.

Em números totais, apresenta-se 608 produções nesse período, sendo que, dessas, 314 centram-se no estado do Rio de Janeiro - majoritariamente na cidade do Rio de Janeiro - e 207 no estado de São Paulo - majoritariamente na cidade de São Paulo. O Rio Grande do Sul, estado que ocupa a terceira fatia do financiamento dos recursos, está bem abaixo desses outros dois: conta com 26 produções financiadas nos 15 anos analisados. Trata-se, assim, de um cenário que necessitava de um aprofundamento e uma maior descentralização para que os recursos que oferecessem espaços não apenas de circulação, mas também de possibilidades para a realização da autossuficiência industrial que se imaginou em 2001 - provavelmente com feições distintas daquela imaginada na formação da Ancine.

\section{A presença dos coletivos audiovisuais}

No segundo nível do fenômeno das produções coletivas da década de 2010, vê-se mais claramente a questão desse novo contexto de alargamento e descentralização das produções. Viu-se surgir no horizonte do cinema e do audiovisual nacional paisagens, locais e narrativas que renovaram a percepção do que caracteriza o cinema brasileiro. Menciona-se aqui o Coletivo de Cinema de Ceilândia (Ceicine), que produziu a trilogia da cidade de Ceilândia, região periférica do Distrito Federal, nos filmes A cidade é uma só, de 2011, Branco sai, preto fica, de 2014, e Era uma vez Brasília, de 2017. As três produções entraram em um circuito de exibição e reconhecimento ao trazerem em suas narrativas uma novidade ao campo. Em certo sentido, era a primeira vez que as periferias se colocavam com as suas narrativas e estéticas em um espaço que nunca tinha sido dado a ela. Essa possibilidade só ocorreu por meio da relação entre a democratização da produção cultural e audiovisual e o consenso do setor de que o caminho para a reconstrução do cinema e do audiovisual brasileiro passava por democratizar o espaço de reconhecimento.

Além do coletivo de Ceilândia, outro local, Contagem, em Minas Gerais, passou a ocupar esse espaço de distinção no campo, alterando o cenário em que foi previamente colocado. São dezenas as produções realizadas no território da cidade pela produtora Filmes de Plástico e todas falam do local em que se passa as suas narrativas, atribuindo à produção e vestindo-se de uma estética do território e de um saber local para oferecer novas visões à produção audiovisual do país. Outro 
exemplo é a Rosza Filmes, das cidades de São Félix e Cachoeira, ambas no Recôncavo Baiano, que participa desse contexto de descentralização e definição de novas prioridades no arranjo redistributivo dos recursos ao setor. O cineasta Ary Rosa e a cineasta Glenda Nicácio, que dirigiu o filme Café com canela, de 2017, notam a relevância da produção que cumpriu a janela completa ao marcar presença em premiações, festivais, incluindo o Festival de Brasília, e sendo exibidas não só nas principais capitais brasileiras, mas também em janelas internacionais. A história do coletivo foi sintetizada em entrevista oferecida para esta pesquisa pelos fundadores, que se formaram no curso de cinema e audiovisual da Universidade Federal do Recôncavo Baiano (UFRB):

A gente fundou a Rosza Filmes em 2011, e Café com canela é de 2017, então tem um percurso de cinco a seis anos para inaugurar uma produção que nos deixou conhecidos no país inteiro. E tudo tem a ver com um entendimento que nós tivemos de forma muito precoce, em 2010 ainda, o porquê uma universidade no interior do Brasil? E essa pergunta mobilizou o nosso discurso de fundação do coletivo e de interiorização do cinema brasileiro e no entendimento em investimento público. Logo a gente entendeu que existia uma estratégia de descentralização de olhares e que pra gente não bastava em importar uma indústria de São Paulo ou do Rio de Janeiro, um cosplay de produção no Recôncavo. Se a gente não criasse uma nova forma de trabalho, de produção e de entendimento seria muito difícil a gente conseguir dar um passo. Assim, três conceitos foram fundamentais: o primeiro, abrir a produtora e ver as indicações, já em 2011 e que em 2013 teria seu auge, de um fundo setorial muito mais ativo e muito menos defensivo no que diz respeito ao retorno econômico, fundamental para a descentralização do cinema; um segundo ponto, o coletivo, uma prática muito presente ao longo dos anos 2000 que a gente conseguiu estabelecer e criar uma condição para que pudéssemos pensar em projetos que não fossem individuais; e um terceiro ponto muito importante é o de economia criativa, um conceito que estava muito forte na época e que nos fez perceber as formas de investimentos que não se restringisse apenas a fundo. O fundamental era que a gente devia conectar esses conceitos com o recôncavo, o que nos fez em 2014 produzir Café com canela com recursos dos arranjos regionais, uma parceria entre ofundo setorial e o governo do estado da Bahia ${ }^{2}$.

${ }^{2}$ Informação fornecida por Ary Rosa em entrevista em 4 de abril de 2020.
A presença dos locais de produção - regiões da periferia dos centros nacionais no centro da política pública cultural foi a grande inovação desse conjunto de ações, arranjos regionais e programas de incentivos municipais. É o que está referido, por exemplo, em uma das ações mais simbólicas deste movimento do setor cultural: os Pontos de Cultura, que são parte do projeto Cultura Viva, criado em 2011.

As matrizes ordenadoras tanto do projeto quanto das ações derivadas dele visavam um fortalecimento territorial das iniciativas culturais com investimento direto do orçamento para as produções em diversas regiões, locais e territórios. Dentre os milhares de projetos atendidos, entre organizações, coletivos e produtoras, vários nunca haviam sido ouvidos por iniciativas públicas de cultura, mesmo estando em locais de acesso a recursos, como São Paulo e Rio de Janeiro, e outros tantos se organizaram a partir do desenho institucional do projeto, vendo nele uma oportunidade de produção que nunca antes havia sido presenciada. O projeto Cultura Viva promoveu um processo de escuta muito relevante para a sobrevivência do setor cultural brasileiro, ainda que também não escape das críticas sobre a sua promoção do local e do território como eixos de planejamento, tornando o espaço artístico e cultural em um campo renovado de produção cultural e de ascensão de novas linguagens, entre as quais notam-se as populares como partes relevantes no âmbito da inovação e criação e não apenas no campo da representação e da aceitação.

Além das iniciativas culturais que fortaleceram a distribuição e a descentralização dos recursos, outro conjunto de políticas auxiliaram nessa inferência no setor audiovisual: por exemplo, a expansão do ensino superior no país. A partir de programas como o Programa de Apoio a Planos de Reconstrução e Expansão das Universidades Federais (Reuni), que fez surgir universidades e institutos federais no interior do país, o Programa Universidade para Todos (ProUni), programa de bolsas em instituições privadas no ensino superior para estudantes de baixa renda, 
e o Fundo de Financiamento Estudantil (Fies), programa de financiamento do ensino superior, novos produtores puderam se formar em diversos territórios do país, bem como novas lógicas e arranjos de produção puderam ser construídos.

Tais arranjos regionais são marcados também pelo FSA e apresentam novas possibilidades de ordenação do setor audiovisual, a partir do eixo territorial proposto como compreensão e consenso da diversidade cultural pelo plano nacional. Essa atuação regionalizada do fundo de investimentos do setor pode ser realizada por editais lançados pela agência ou, em contrapartida, a partir das secretarias estaduais dos estados e do Distrito Federal. Um bom exemplo de ação pelos estados é o arranjo produzido pela Bahia com o lançamento de editais setoriais que promovem as diversidades raciais, territoriais e de gênero como critérios a serem considerados na escolha dos projetos audiovisuais. A composição com os arranjos regionais fez a produção se descentralizar de 2010 a 2018, como mostra o gráfico da Figura 3.

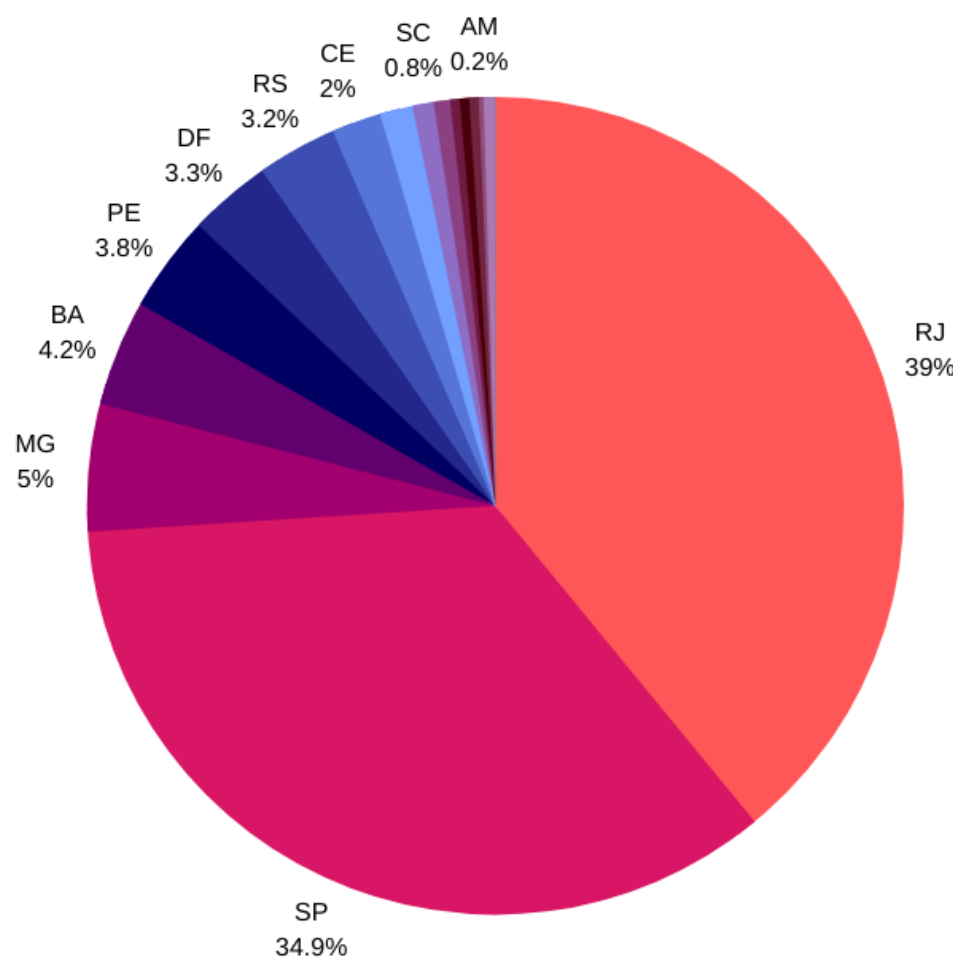

Dados: Observatório Brasileiro do Cinema e do Audiovisual

Figura 3 Dados de investimentos para produções audiovisuais entre os anos de 2010 e 2018

A primeira notação importante é o crescimento considerável das produções na Bahia, bem como no Distrito Federal e em Minas Gerais, por interferência direta dos arranjos regionais do FSA. Ainda que haja uma predominância de produções advindas de São Paulo e do Rio de Janeiro, o que também não poderia ser distinto por se tratarem de espaços consolidados dentro do setor audiovisual, é importante marcar a presença de novos territórios produtores em relação ao que existia no gráfico da Figura 2 e as suas principais razões.

\section{Daqui para o futuro}

As menções às práticas coletivas nas periferias auxiliarão em parte a compreender a ação dos coletivos nas décadas 2000 e 2010. Importante, entretanto, é marcar que esse processo ocorre há mais tempo do que há duas décadas como uma forma existente de produção cultural, assim como se estabeleceu nas periferias de São Paulo e em outros territórios nacionais. Vale mencionar a importância do hip hop nesse contexto como não apenas uma expressão cultural, mas também um contribuinte, devido aos arranjos culturais que ele propõe como práxis aos locais periféricos. $\mathrm{O}$ mesmo pode ser dito sobre o audiovisual das periferias, que, desde sua base, caracteriza-se como produções mais coletivas e horizontais por essas serem as formas que tais locais encontram de existir diante de muitas outras dificuldades. 
Essa realidade se alterou ao longo do tempo, a partir de iniciativas culturais e políticas públicas do setor - ainda que este se ausente de oferecer muitas outras oportunidades e apresente limites, como tentamos expor -, e, atualmente, nota-se nessas produções a presença da diversidade em dois sentidos: a do território, que marca a função do local nas paisagens e narrativas audiovisuais, e a identitária, que alia o território aos debates raciais, das negritudes, de gênero, dos feminismos plurais e LGBTQIA+, entre outros. Os coletivos Gleba do Pêssego e Maloka Filmes são exemplos do que se expõe.

O coletivo Gleba, por incentivo do Programa para a Valorização de Iniciativas Culturais (VAI) da cidade de São Paulo, voltado aos territórios periféricos, produziu o curta-metragem Bonde, que relaciona existências identitárias com as questões territoriais e os danos sociais, como o racismo e a LGBTfobia. O curta também oferece a perspectiva de se pensar as formas de experiências sociais pela presença e, principalmente, pela ausência de direitos no cotidiano dos grupos sociais representados na narrativa, em que também fazem parte os produtores do filme. Isso também se presencia no curta-metragem da Maloka Filmes, Perifericu, que também é narrado por meio de um projeto multiplataforma, em uma série documental para o YouTube. Ambas as narrativas traduzem a relação entre as formas identitárias nas periferias, as suas relações com o local e a busca por uma identidade coletiva que una as experiências em ser LGTQIA+ nos territórios periféricos.
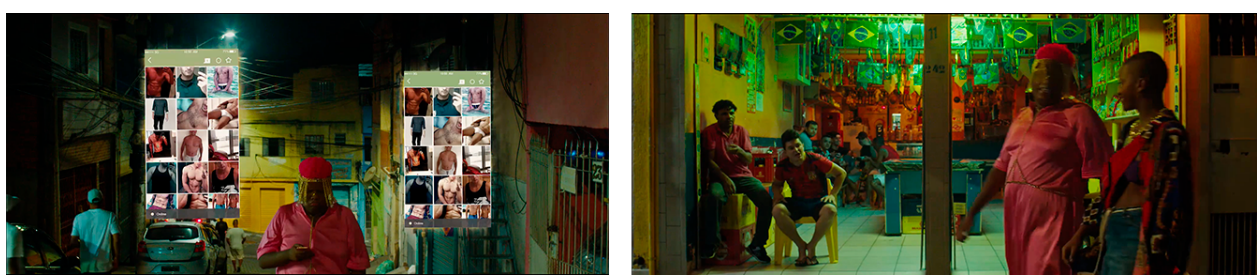

Figura 4 As paisagens das periferias em Bonde

Não faria sentido não falar sobre isso. Ainda que seja uma ficção, é a nossa vivência também ali. Gravamos na quebrada em Heliópolis e esse processo de campo de escolha do espaço foi muito cuidadoso, pra gente não só chegar e gravar, a gente tinha que compreender tudo ali. E teve um processo de diálogo entre nós e entre pessoas de outras periferias para entender se era isso mesmo. É proposital pois não teria como fazer de outro jeito, escolher três protagonistas negras, Bonde é uma ficção, mas fala muito do que a gente é. (Venanzoni, 2021, p. 192)

O arranjo de produção em coletivos periféricos necessariamente está em adesão ao território e às suas formas de expressão. A importância das produções periféricas de baixo orçamento, das produções que não teriam outras formas de existência, das produções experimentais, das produções universitárias, entre outras, reside no fato de que elas servem como base dual de dois aspectos: a diversidade e a democratização do audiovisual. Sem a presença desses arranjos de produção no orçamento do cinema e do audiovisual, tendemos a estagnar como uma indústria restrita e distante da autossuficiência.

Esse alargamento e descentralização necessita, portanto, ser constante e alinhado a outros projetos e demandas que possam surgir no futuro. Entendeu-se que o projeto cultural para o audiovisual e em ampliação para outros setores deve ser pela via da democratização e da redistribuição e não apenas por produções que garantem, em certo sentido, lucratividade para o setor audiovisual e para a sua autossuficiência como industrial global. A partir da descentralização da produção foi possível detectar a emergência de novos arranjos produtivos que levam em conta, sobretudo, o território e o seu local produtor. Esse emblema do território, que se atualiza pelo discurso da diversidade, pode também ser visto pelo ponto de vista conceitual, ou seja, a dimensão local em contraposição a global e como um espaço de produção de novas narrativas.

Essa questão, já debatida em transformações sociais vistas desde a década de 1980 com o assolamento global, traz tanto a ideia de unificação como a de surgimento de uma nova conjuntura hegemônica que faz emergir espaços e brechas 
a contrapelo em formas contra-hegemônicas. Essa nova disputa se encontra na base de uma sociologia decolonial que discutimos a partir de teóricos como Jesús Martín-Barbero (2014) e Milton Santos (2000; 2005). É evidente que há uma imensidão muito maior de teóricos e sociólogos que trabalham as mesmas bases aqui apresentadas, porém nossa intenção não passa pela construção de sínteses e filiações desse pensamento, mas sim pela articulação de determinadas noções dessa sociologia a partir de Martín-Barbero e Santos. Entre as noções a serem trabalhadas se encontra a relação entre o saber local e a produção de identidades em renovadas produções culturais e audiovisuais.

De acordo com esse pensamento, a globalização é uma narrativa oferecida pelos mercados hegemônicos como uma superestrutura que atinge espaços diversos da vida cotidiana, incluso nesse agrupamento e diapasão o mercado cultural. Para Milton Santos (1999), a globalização se caracteriza como uma fábula à medida que engloba para si, em sua dinâmica de unificação de mercado, relações simbólicas, identitárias e, em evidência, o que deve ser consumido. Como uma fábula, faz crer que esse modelo é acessível a todos, em formas distintas de acesso material, simbólico e identitário, porém esconde a sua perversidade nessa forma de relação em que a acessibilidade depende da forma com que se entra no jogo global e que também passa a ser lida como um privilégio, não como um direito à cidadania. Ainda, nessa relação se experencia uma tensão recorrente entre a possibilidade de alargamento e democratização da cultura e a diminuição do espaço de acesso a ela. Não por outro motivo a ideia de cultura como um direito está na base do PNC.

Ao mesmo tempo que a globalização unifica e perverte as relações sociais com sua fábula, para Martín-Barbero, ela

[...] também representa um conjunto extraordinário de possibilidades, mudanças possíveis agora e que se apoiam em fatos radicalmente novos, destacando-se dois deles: um, a enorme e densa mistura de povos, raças, culturas e gostos que acontece hoje - embora com grandes diferenças e assimetrias - em todos os continentes, uma mistura somente possível na medida em que outras cosmovisões emergem com grande força, pondo em crise a hegemonia do racionalismo ocidental; o outro, as novas tecnologias que vêm sendo progressivamente apropriadas por grupos dos setores subalternos, permitindo-lhes uma verdadeira revanche sociocultural, isto é, a construção de uma contra-hegemonia pelo mundo. (Martín-Barbero, 2012, p. 18, adaptado)

É válido pensar, ainda, que as possibilidades extraordinárias citadas pelo sociólogo dizem respeito também a uma nova dinâmica que o digital oferece não apenas no aprofundamento da unificação dos mercados globais e a sua desterritorialização, mas também às possibilidades de novas produções e novos arranjos locais e culturais. No caminho da articulação, Milton Santos (2005) vai trazer toda a base de reflexão sobre o saber local e a noção do espaço como uma prática cultural:

O espaço é a matéria trabalhada por excelência. Nenhum dos objetos sociais tem uma tamanha imposição sobre o homem, nenhum está tão presente no cotidiano dos indivíduos. A casa, o lugar de trabalho, os pontos de encontro, os caminhos que unem esses pontos são igualmente elementos passivos que condicionam a atividade dos homens e comandam a prática social. A práxis, ingrediente fundamental da transformação da natureza humana, é um dado socioeconômico, mas é também tributária dos imperativos espaciais. (Santos, 2005, p. 34)

Assim, o espaço é o lugar de fluxos, transformações e saberes. Sua condição é estrutural e, portanto, de mudança frente aos paradigmas insurgidos pelas relações sociais presentes no território habitado. Também por essa razão, as políticas culturais mais inovadoras buscam os saberes locais, não o oposto, pois assim locais com pouco acesso não são impostos às formas culturais e artísticas como se nesses territórios não houvesse cultura. Não haveria, assim, um projeto organizado para a oferta aos diversos territórios a não ser o de dar aos locais condições de produção, pois "o espaço reproduz-se, ele mesmo, no interior da totalidade, quando evolui em função do modo de produção e de seus momentos sucessivos" (Santos, 2005, p. 33). 
Neste ponto encontramos a síntese que buscamos ao articularmos um projeto de política pública desenvolvido para o setor cultural e audiovisual às teses que balizam esse pensamento e às produções que emergiram desse contexto. Nossa hipótese, portanto, centraliza-se em apresentar a maneira pela qual as dimensões territoriais, vistas a partir da diversidade cultural no PNC, nos arranjos regionais do FSA e nas iniciativas locais de incentivo cultural, fizeram emergir arranjos produtivos renovados a partir, por exemplo, de coletivos audiovisuais que acionam o lugar tanto na organização da produção audiovisual como no discurso ou enunciação da diversidade.

Com esses três níveis estruturados, o que demonstra ser uma presença cada vez mais ativa no cenário produtivo e industrial do cinema e audiovisual nacional, efetivase uma mudança nos espaços de produção provocada por uma mudança na base consensual do setor cultural, no alargamento democrático dessas duas últimas décadas e das novas marcas e narrativas sociais. Essa é a dimensão pensada neste artigo para se referir ao porvir, a um lugar em que devemos buscar, conjuntamente, modelos de reconhecimento e novos investimentos para que outras narrativas periféricas, outros visionamentos locais e regionais que debatem outras questões territoriais possam se materializar em representação às formas discursivas existentes neste momento.

Fala-se, portanto, em um processo de industrialização do cinema e do audiovisual que, mesmo tendo passado por uma reconfiguração do modelo pensado no começo do século, da formação da agência e da ideia de autossuficiência, ainda necessita de uma ampliação no horizonte das produções e, de alguma forma, de uma inversão das prioridades. Há no interior do campo gestores e produtores audiovisuais que pensam em remeter a indústria nacional aos modelos de outros países e lugares, muito embora tal pensamento não pareça ser mais um consenso. A esse respeito, parece válido sempre reafirmar que a redistribuição deve caminhar junto às formas de reconhecimento dentro do setor, o que foi percebido como necessidade nos últimos anos.

Daqui para o futuro, o cinema e a produção cultural devem ser ainda mais territorializado ao que se apresentou nas décadas 2000 e 2010. No momento mais grave para o setor cultural no Brasil, houve uma tentativa de regionalização com a saída de projetos culturais referidos pela Lei Aldir Blanc, de 2020, e com toda a discussão e aprovação da Lei Paulo Gustavo em 2021. Ambas as leis buscam aumentar a regionalização dos incentivos culturais e diminuir a enorme dificuldade que se encontra na captação dos recursos fundamentais para a cultura pela União por parte de produtores e gestores culturais, em decorrência das ingerências dentro dos órgãos federais de cultura.

Porém, se o caminho para a descentralização da produção passa por um entendimento relevante com esses dois exemplos, no caso do audiovisual há dificuldades que avançam sobre essas questões. Por exemplo, os limites dos arranjos regionais do FSA passam neste momento por uma situação crítica de investimentos nos recursos já disponíveis - mobilizados, como dito, por ingerências de uma política ideologizada e perversa. Ainda assim, em situações normalizadas, entende-se a necessidade de um aperfeiçoamento dessa política de investimentos do fundo no cinema e audiovisual. Adiciona-se a essa dificuldade a compreensão da necessidade de um alargamento em relação às janelas e espaços de exibição que descentralizam o acesso a elas.

Um passo já tem sido dado pelos investimentos públicos para a distribuição audiovisual em circuitos alternativos, por meio da exigência da exibição nacional em redes de salas de cinema e de licenciamento para canais de tv por assinatura, aspectos que não foram debatidos neste artigo, mas que fazem parte de um contexto mais amplo de democratização da produção e do acesso à produção. Porém, há um espaço ainda em disputa de sentidos e políticas que parece ser um caminho a ser enfrentado na próxima década.

\section{Conclusão}

Se o dever é pensar em uma autossuficiência industrial que recolhe tributos das grandes produções, licenciadoras, distribuidoras e exibidoras, como as plataformas 
globais de streaming, e repassa para as produções experimentais, periféricas e de baixo orçamento que não provocam interesse comercial das majors, não há como pensar fora de um recolhimento justo desses tributos e de uma redistribuição que passa pelo reconhecimento de produções periféricas.

É possível pensar, igualmente, em uma estratégia pública para a exibição e a distribuição dessas produções. Portanto, mostra-se urgente pensar em tributações específicas das plataformas globais que financiem a existência de plataformas públicas de exibição das produções periféricas que buscam visibilidade e reconhecimento, além, claro, das formas de recolhimento tributário que a contribuição para o desenvolvimento da indústria cinematográfica nacional já realiza e remete ao FSA, impactando as produções nacionais. Esse parece ser um caminho para o debate nos próximos anos, uma vez que em 2020, ano da pandemia da covid-19, tais mecanismos se mostraram capazes de desenvolver iniciativas digitais para o audiovisual, o que pode caracterizar um aprofundamento das desigualdades nesse setor, caso não tenhamos atenção ao movimento do mercado global.

Se a plataformização do audiovisual parece ser um caminho cada vez mais evidente para a distribuição de grandes produções e produções de baixíssimo custo, há, ao menos, dois problemas que se vislumbram no momento atual desses serviços, em que também se discute a democratização e a diversidade da produção audiovisual. O primeiro, e o mais importante, é a ausência de registro dessas plataformas globais no Brasil e, por essa razão, o não pagamento de tributos das plataformas para o Condecine, por exemplo. Ou seja, as plataformas não investem indiretamente e, caso haja um investimento, é voltado para determinados produtos e não contempla a necessidade da continuidade do audiovisual brasileiro. O segundo problema é a pouca produção nacional existente nessas plataformas globais de distribuição. Tratam-se, assim, de duas questões sobre um mesmo problema.

Ressalta-se, ainda dentro desse cenário de mudanças, a eficiência da Lei № 12.485, que corre o risco de inocuidade e uma clara tendência de menor recolhimento pelo mecanismo dessa lei, uma vez que se percebe uma migração do consumo da TV por assinatura para os serviços de streaming. Isso significa um movimento de migração das empresas e produtoras de conteúdo para a TV paga em direção aos serviços de streaming, criando as suas próprias plataformas, como a Disney, a Warner, a Viacom, entre outras. Nesses casos, essas empresas podem vir a questionar a aderência da lei e a sua jurisprudência. Dessa forma, é urgente o debate sobre a plataformização do audiovisual e a sua relação com a sobrevivência das novas tendências do audiovisual brasileiro. Enfrentar a marginalização e as desigualdades do audiovisual do país deve ser prioridade para o próximo legado de pesquisadores.

Por fim, os últimos vinte anos nos apresentaram formas de alargamento da produção audiovisual no Brasil, uma base cultural sólida e consensual que fez surgir novas formas e arranjos de produção, referidas neste artigo pelos coletivos audiovisuais. O princípio que guiou essa política nacional em prol da democratização, do acesso e da descentralização da produção agora colhe frutos e passa a caminhar para um aprofundamento dessas políticas culturais, o que deve ser seguido pelo setor audiovisual. Além disso, é nosso papel como gestores, curadores, pesquisadores, produtores e demais interessados no cinema e no audiovisual nacional buscar alternativas para contornar as novas maneiras de assolamento global que se materializam nas plataformas audiovisuais globais e em modelos sustentáveis, a fim de que elas coexistam com as alternativas públicas ou independentes de serviços que contrapõem a lógica global, novamente com as potencialidades e as resistências locais.

\section{REFERÊNCIAS BIBLIOGRÁFICAS}

Caffé, C. (2017). Era o hotel Cambridge: arquitetura, cinema e educação. Sesc.

Ikeda, M. (2015). As leis de incentivo e a política cinematográfica no Brasil a partir da "retomada". Revista Eptic, 17(3), 163-177. 
Martín-Barbero, J. (2014). Diversidade em convergência. MATRIZes, 8(2), 15-33. https://doi.org/10.11606/issn.1982-8160.v8i2p15-33

Ministério da Cultura. (2007). Diretrizes gerais para o plano nacional de cultura. Ministério da Cultura.

MORAIS, K. S. (2019). Cota de tela (Lei no 12.485/2011) e a produção independente na TV paga. Significação, 46(52), 270-292. https://doi.org/10.11606/issn.23167114.sig.2019.147815

Ortiz, R. (2015). Universalismo e diversidade: contradições na modernidademundo. Boitempo.

Santos, M. (1999). O território e o saber local: algumas categorias de análise. Cadernos IPPUR, 13(2), 15-26.

Santos, M. (2000). Por uma outra globalização: do pensamento único à consciência universal. Record.

Santos, M. (2005). Espaço e método. Edusp.

Venanzoni, T. S. (2021). Diversidade social e políticas culturais: práticas discursivas e coletivas no audiovisual brasileiro contemporâneo. (Tese de Doutorado). Universidade de São Paulo, São Paulo, SP, Brasil. 